OPEN ACCESS

Edited by:

Guoxiang Cai,

Fudan University, China

Reviewed by:

Renjie Wang,

Fudan University, China

Hyeonhoon Lee,

Kyung Hee University, South Korea

*Correspondence:

Jung Wook Huh

jungwook.huh@gmail.com

Specialty section:

This article was submitted to Gastrointestinal Cancers:

Colorectal Cancer,

a section of the journal

Frontiers in Oncology

Received: 21 September 2021 Accepted: 13 December 2021

Published: 06 January 2022

Citation:

Lim JH, Huh JW, Lee WY, Yun SH, Kim HC, Cho YB, Park YA and Shin JK (2022) Comparison of

Long-Term Survival Outcomes of T4a and T4b Colorectal Cancer.

Front. Oncol. 11:780684.

doi: 10.3389/fonc.2021.780684

\section{Comparison of Long-Term Survival Outcomes of T4a and T4b Colorectal Cancer}

\author{
Ji Ha Lim, Jung Wook Huh ${ }^{*}$, Woo Yong Lee, Seong Hyeon Yun, Hee Cheol Kim, \\ Yong Beom Cho, Yoon Ah Park and Jung Kyong Shin
}

Department of Surgery, Samsung Medical Center, Sungkyunkwan University School of Medicine, Seoul, South Korea

Background: Although T4b is known to have worse oncologic outcomes, it is unclear whether it truly shows a worse prognosis. This study aims to compare the survival differences between $\mathrm{T} 4 \mathrm{a}$ and $\mathrm{T} 4 \mathrm{~b}$.

Methods: Patients who were pathologically diagnosed with T3 and T4 colorectal adenocarcinoma from 2010 to 2014 were included (T3, $n=1822$; T4a, $n=424$; T4b, $n=67)$. Overall survival (OS) and cancer-specific survival (CSS) were compared between T4a and T4b using the Kaplan-Meier method and log-rank test.

Results: In stage II, T4a had better OS and CSS than T4b (5-year OS, 89.5\% vs. 72.6\%; 5 -year CSS, 94.4\% vs. 81.7\%, all p < 0.05), however, in stage III, there were no significant differences in survivals between groups (all $\mathrm{p}>0.05$ ). In multivariable analysis, $T$ classification was not an independent risk factor for OS ( $p>0.05)$. However, for CSS, when respectively compared to $\mathrm{T} 3, \mathrm{~T} 4 \mathrm{~b}(\mathrm{HR} 3.53, \mathrm{p}<0.001)$ showed a relatively higher hazard ratio than T4a (HR 2.27, $\mathrm{p}<0.001)$.

Conclusions: T4a showed more favorable OS and CSS than T4b, especially in stage II. Our findings support the current AJCC guidelines, in which T4b is presented as a more advanced stage than T4a.

Keywords: AJCC guideline, colorectal cancer, serosal exposure, organ invasion, survival

\section{INTRODUCTION}

Colorectal cancer (CRC) is one of the most common types of cancer. In 2017, it was the second most common malignancy, following gastric cancer, and had the third-highest cancer mortality rate in South Korea (1). The incidence of CRC remains high compared to that of other cancers. To allow doctors to design treatment plans and determine a prognosis for each patient, patients diagnosed with CRC are often classified according to the American Joint Committee on Cancer (AJCC)'s tumor-node-metastasis (TNM) staging system.

In the 7th edition of the AJCC guidelines on colorectal cancer, stage T4 was divided into T4a and T4b (2). T4b may be considered more severe due to other organs/structural invasion, and several studies confirmed that T4b showed worse outcomes than T4a (3-5). However, T4a tumor that invades the free serosa may have a greater chance of peritoneal seeding (6-8), and it is still unclear and controversial whether T4a tumors are truly associated with a better prognosis than $\mathrm{T} 4 \mathrm{~b}$ tumors 
(6-10). The purpose of this study is to compare the long-term survival outcomes of patients with $\mathrm{T} 4 \mathrm{a}$ and $\mathrm{T} 4 \mathrm{~b}$ tumors and determine if there are any differences in the outcomes.

\section{MATERIALS AND METHODS}

The records of patients who were first diagnosed with colorectal adenocarcinoma and underwent surgery in Samsung Medical Center (SMC) from January 2010 to December 2014 were collected for this study. Pathologically confirmed T3 and T4 patients who underwent curative-intent surgery with R0 resection were included. Patients with (1) stage IV disease, (2) recurrent colorectal cancer, (3) hereditary colorectal diseases, (4) no records of preoperative carcinoembryonic antigen (CEA)/carbohydrate antigen (CA) 19-9, (5) neoadjuvant chemotherapy with or without radiotherapy, (6) other organ malignancies and (7) mid to lower rectal cancer were excluded. As a result, a total of 1822 patients were analyzed. We obtained approval from the Institutional Review Board of Samsung Medical Center (SMC 2021-01-070).

Collected baseline characteristics included age, sex, body mass index (BMI), American Society of Anesthesiologists (ASA) score, preoperative CEA, and CA 19-9 level. All tissue samples taken after colectomy or proctectomy were evaluated and confirmed by several pathologists based on AJCC guidelines (8th edition) (11). The definitions of T3, T4a, and T4b in the guidelines are as follows: T3, tumor invades through the muscularis propria into peri-colorectal tissues; T4a, tumor penetrates the surface of the visceral peritoneum; $\mathrm{T} 4 \mathrm{~b}$, tumor directly invades or is adherent to other organs or structures $(2,9)$. We also obtained data on tumor size; pathologic tumor-nodal stage; lymphatic, vascular, and perineural invasion; tumor budding; and microsatellite instability (MSI) status for all patients. Each patient underwent colectomy or proctectomy according to the location of the tumor (12-14).

If tumor invasion or adhesion to other organs were found, enbloc resection was conducted. The right colon included the cecum to the mid-transverse colon, and the left colon included the distal transverse colon to the rectosigmoid colon. Postoperative complications were classified by the ClavienDindo classification (CDC) system $(15,16)$. Patients who had complications of grade III, which requires surgical, endoscopic, or radiological intervention, and higher were investigated. Readmission was defined as admission again within 30 days after discharge.

Adjuvant therapy was done according to the National Comprehensive Cancer Network (NCCN) guidelines. In patients who refused recommended chemotherapy, routine follow-up was performed as in all other non-chemotherapytreated patients. Patients were first followed up within two weeks after discharge, then every 3 months for 2 years, and then every 6 months until 5 years after surgery. After that, the further followup period was determined at the discretion of the surgeons. Follow-up examination included serum CEA level, chest CT, APCT or MRI, colonoscopy, and EGD or PET-CT, if recurrence was suspected.
The primary outcome was long-term survival outcome and the secondary outcome was pathologic differences between T4a and T4b tumors.

All statistical analyses were performed using SAS version 9.4 (SAS Institute Inc, Cary, NC, USA) and SPSS (version 27.0, SPSS Inc., Chicago, IL). A p-value of $<0.05$ was considered statistically significant. Comparisons among the T3, T4a, and T4b groups were performed using $\chi 2$ or Fisher's exact test as needed for categorical variables, while the Kruskal-Wallis test was used for continuous variables. Post-hoc analysis was performed for variables with a p-value of less than 0.05 among the three groups. The survival rates and curves were expressed using the KaplanMeier method and compared using log-rank tests. Cox regression analysis of overall survival (OS) and cancer-specific survival (CSS) was conducted to identify the factors that have an influence on survivals. After screening for significant variables in univariable regression, it was estimated through variable selection using backward elimination method in multivariable Cox regression. Multicollinearity was reviewed as a variance inflation factor (VIF), and variables with abnormally large VIFs were excluded from the final model.

\section{RESULTS}

A total of 1822 patients who underwent surgery for colorectal cancer from 2010 to 2014 and who were pathologically confirmed to have T3 and T4 colorectal cancer were included in the study ( $\mathrm{T} 3, \mathrm{n}=1822$; $\mathrm{T} 4 \mathrm{a}, \mathrm{n}=424$; $\mathrm{T} 4 \mathrm{~b}, \mathrm{n}=67$ ).

A comparison of baseline characteristics among the T3, T4a, and $\mathrm{T} 4 \mathrm{~b}$ groups is presented in Table 1. There were no statistically significant differences in age, sex, ASA score, or the number of tumors among the three groups. Following post-hoc analysis, the proportions of patients who showed elevated preoperative CEA levels and cancer obstruction were not significantly different between the T4a and T4b groups. More T4b than T4a patients showed elevated preoperative CA 19-9 levels (31.3\% vs. $17.0 \%$, respectively; post-hoc $\mathrm{p}=0.026)$. Moreover, more $\mathrm{T} 4 \mathrm{~b}$ patients presented with cancer perforation than $\mathrm{T} 4 \mathrm{a}$ patients $(10.5 \%$ vs. $2.8 \%$, respectively; post-hoc $\mathrm{p}=0.023)$, and the mean tumor size was larger in T4b than T4a patients $(8.07 \pm 2.89 \mathrm{~cm}$ vs. $4.95 \pm 3.00 \mathrm{~cm}$, posthoc $\mathrm{p}<0.001)$. More T4b cases were emergent and open cases (emergent operation, $11.9 \%$ vs. $3.3 \%, \mathrm{p}=0.013$; open surgery, $68.6 \%$ vs. $17.7 \%, \mathrm{p}<0.001)$. T4b patients also showed a longer mean operation time $(223.03 \pm 107.53 \mathrm{~min}$ vs. $159.40 \pm 62.74$ min, post-hoc $\mathrm{p}<0.001)$. T4a patients showed the same proportion of right and left colon involvement (37\% each), but T4b was more often seen on the right side (right colon, $47.8 \%$; left colon, 22.4\%) (post-hoc $\mathrm{p}=0.018$ ) (Table 1).

Regarding pathologic outcomes, all investigated pathologic variables showed statistically significant differences among T3, $\mathrm{T} 4 \mathrm{a}$, and T4b patients; however, in the post-hoc analysis, only nodal status, number of positive lymph nodes, and lymphatic and perineural invasion showed significantly differed between the T4a and T4b groups. T4a patients showed higher nodal status (N1, 
TABLE 1 | Baseline characteristics of the study subjects.

\begin{tabular}{|c|c|c|c|c|c|c|}
\hline Parameters & Total $(n=1822)$ & T3 $(n=1331)$ & T4a $(n=424)$ & T4b $(n=67)$ & p-value & $\begin{array}{c}\text { post hoc } \\
\text { p-value }\end{array}$ \\
\hline Age, mean $\pm S D$, years & $60.73 \pm 11.67$ & $60.64 \pm 11.51$ & $61.10 \pm 11.99$ & $60.39 \pm 12.91$ & & \\
\hline \multicolumn{7}{|l|}{ Sex } \\
\hline Male & 1049 (57.6\%) & 775 (58.2\%) & 243 (57.3\%) & 31 (46.3\%) & 0.153 & \\
\hline Female & 773 (42.4\%) & 556 (41.8\%) & 181 (42.7\%) & 36 (53.7\%) & & \\
\hline 1 & $651(35.7 \%)$ & 478 (35.9\%) & $153(36.1 \%)$ & 20 (29.9\%) & 0.114 & \\
\hline 2 & 1092 (59.9\%) & $802(60.3 \%)$ & 244 (57.6\%) & $46(68.7 \%)$ & & \\
\hline 3 & 79 (4.4\%) & $51(3.8 \%)$ & $27(6.3 \%)$ & $1(1.4 \%)$ & & \\
\hline \multicolumn{7}{|l|}{ Preoperative CEA } \\
\hline$\geq 5 \mathrm{ng} / \mathrm{ml}$ & 506 (27.8\%) & 338 (25.4\%) & 137 (32.3\%) & 31 (46.3\%) & $<0.001$ & 0.107 \\
\hline$<5 \mathrm{ng} / \mathrm{ml}$ & $1316(72.2 \%)$ & $993(74.6 \%)$ & $287(67.7 \%)$ & $36(53.7 \%)$ & & \\
\hline Yes & $414(22.7 \%)$ & $234(17.6 \%)$ & $145(34.2 \%)$ & 35 (52.2\%) & $<0.001$ & 0.201 \\
\hline No & $1408(77.3 \%)$ & $1097(82.4 \%)$ & $279(65.8 \%)$ & $32(47.8 \%)$ & & \\
\hline \multicolumn{7}{|l|}{ Cancer Perforation } \\
\hline Yes & $19(1.0 \%)$ & $0(0 \%)$ & $12(2.8 \%)$ & 7 (10.5\%) & $<0.001$ & 0.023 \\
\hline No & 1803 (99.0\%) & $1331(100 \%)$ & $412(97.2 \%)$ & $60(89.5 \%)$ & & \\
\hline \multicolumn{7}{|l|}{ Tumor location } \\
\hline Right colon & 527 (28.9\%) & $338(25.4 \%)$ & $157(37.0 \%)$ & 32 (47.8\%) & $<0.001$ & 0.018 \\
\hline Left colon & $687(37.7 \%)$ & $515(38.7 \%)$ & $157(37.0 \%)$ & $15(22.4 \%)$ & & \\
\hline Rectum & $608(33.4 \%)$ & $478(35.9 \%)$ & $110(26.0 \%)$ & $20(29.8 \%)$ & & \\
\hline Tumor size, mean $\pm \mathrm{SD}, \mathrm{cm}$ & $5.12 \pm 2.41$ & $5.02 \pm 2.05$ & $4.95 \pm 3.00$ & $8.07 \pm 2.89$ & $<0.001$ & $<0.001$ \\
\hline \multicolumn{7}{|l|}{ Type of surgery } \\
\hline Elective & $1784(97.9 \%)$ & 1315 (98.8\%) & $410(96.7 \%)$ & 59 (88.1\%) & $<0.001$ & 0.013 \\
\hline Emergent & $38(2.1 \%)$ & $16(1.2 \%)$ & $14(3.3 \%)$ & $8(11.9 \%)$ & & \\
\hline
\end{tabular}

SD, standard deviation; BMI, body mass index; ASA, American Society of Anesthesiologists; CEA, carcinoembryonic antigen; CA 19-9, Carbohydrate antigen 19-9; MIS, minimally invasive surgery.

a)This includes hand-assisted laparoscopy, total laparoscopy, and robotic surgery.

$32.8 \%$ vs. $43.6 \%$; $2,19.4 \%$ vs. $30.2 \%$, post-hoc $\mathrm{p}<0.001)$ and a greater mean number of positive lymph nodes $(2.00 \pm 3.41$ vs. $2.71 \pm 3.03$, post-hoc $\mathrm{p}=0.044)$. Lymphatic and perineural invasion were also more common in T4a than T4b (lymphatic invasion, $38.8 \%$ vs. $59.0 \%$, post-hoc $\mathrm{p}=0.001$; perineural invasion, $34.3 \%$ vs. $52.4 \%$, post-hoc $\mathrm{p}=0.003)$. MSI-high $(\mathrm{MSI}-\mathrm{H})$ colorectal cancer patients were more in T4b groups (5.2\% vs. $17.9 \%$, post-hoc $\mathrm{p}<0.001$ ). In postoperative outcome, Clavien-Dindo classification (CDC) grade 3 or higher postoperative complications were more common in T4b patients than in T4a patients $(11.9 \%$ vs. $3.3 \%$, post-hoc $\mathrm{p}=0.013)$. Adjuvant chemotherapy was performed in $73.1 \%$ of all cases (T3, 67.7\%; T4a, 89.2\%; T4b, 79.1\%) and the chemotherapy completion rate was $91.6 \%$ (T3, 92.0\%; T4a, $90.5 \%$; $\mathrm{T} 4 \mathrm{~b}, 92.5 \%)$. There were no significant differences in the rates of readmission, recurrence, or mortality between the $\mathrm{T} 4 \mathrm{a}$ and $\mathrm{T} 4 \mathrm{~b}$ groups (all p > 0.05) (Table 2).

\section{Overall Survival (OS)}

We compared OS among the T3, T4a, and T4b groups by stage. The median follow-up period was 66 months $(0.5-128)$. In patients with stage II cancer, the 5-year OS rates were $93.8 \%$ for $\mathrm{T} 3,89.5 \%$ for $\mathrm{T} 4 \mathrm{a}$, and $72.6 \%$ for $\mathrm{T} 4 \mathrm{~b}$ patients. This difference was statistically significant $(\mathrm{p}=0.013)$, and there was also a significant difference between the $\mathrm{T} 4 \mathrm{a}$ and $\mathrm{T} 4 \mathrm{~b}$ groups $(\mathrm{p}=$ 0.043 ). In stage III patients, the 5 -year OS rates were $88.1 \%$ for $\mathrm{T} 3,72.4 \%$ for $\mathrm{T} 4 \mathrm{a}$, and $66.0 \%$ for $\mathrm{T} 4 \mathrm{~b}$ patients. This difference was also statistically significant $(\mathrm{p}<0.001)$, but there was no significant difference between the $\mathrm{T} 4 \mathrm{a}$ and $\mathrm{T} 4 \mathrm{~b}$ groups $(\mathrm{p}=$ 0.831 ). Figure 1 shows the OS curves of the three groups.

In multivariable Cox regression analyses, cell type, lymphatic invasion, and tumor budding were excluded from the final models to avoid multicollinearity. Age less than 60 (HR 0.39, 95\% CI $0.20-0.74, \mathrm{p}=0.004)$ and adjuvant chemotherapy (HR $0.32,95 \%$ CI $0.16-0.61, \mathrm{p}=0.001$ ) were independent factors associated with improvements in OS, while cancer perforation (HR 5.00, 95\% CI 1.51-16.52, $\mathrm{p}=0.008$ ) and perineural invasion (HR 1.93, 95\% CI 1.01-3.67, $\mathrm{p}=0.045$ ) were independent risk factors. T classification was not a significant independent risk factor (T3, reference; T4a, HR 1.20, 95\% CI 0.53-9.58, p > 0.999; T4b, HR 2.26, 95\% CI 0.53-9.58, $\mathrm{p}=0.532$ ) (Table 3). 
TABLE 2 | Postoperative outcomes.

\begin{tabular}{|c|c|c|c|c|c|c|}
\hline Parameters & Total $(n=1822)$ & T3 $(n=1331)$ & T4a $(n=424)$ & T4b $(n=67)$ & p-value & $\begin{array}{c}\text { post hoc } \\
\text { p-value }\end{array}$ \\
\hline \multicolumn{7}{|l|}{ Cell differentiation } \\
\hline WD & 334 (18.3\%) & 285 (21.4\%) & 44 (10.4\%) & $5(7.5 \%)$ & \multirow[t]{3}{*}{$<0.001$} & \multirow[t]{3}{*}{0.792} \\
\hline MD & 1384 (76.0\%) & $990(74.4 \%)$ & $342(80.7 \%)$ & $52(77.6 \%)$ & & \\
\hline PD & $104(5.7 \%)$ & $56(4.2 \%)$ & $38(8.9 \%)$ & 10 (14.9\%) & & \\
\hline \multicolumn{7}{|l|}{ Nodal status } \\
\hline NO & 790 (43.4\%) & 647 (48.6\%) & $111(26.2 \%)$ & 32 (47.8\%) & \multirow[t]{3}{*}{$<0.001$} & \multirow[t]{3}{*}{$<0.001$} \\
\hline N1 & $676(37.1 \%)$ & 469 (35.2\%) & 185 (43.6\%) & 22 (32.8\%) & & \\
\hline N2 & $356(19.5 \%)$ & 215 (16.2\%) & $128(30.2 \%)$ & $13(19.4 \%)$ & & \\
\hline Positive lymph node, mean $\pm S D, n$ & $1.90 \pm 2.85$ & $1.63 \pm 2.71$ & $2.71 \pm 3.03$ & $2.00 \pm 3.41$ & $<0.001$ & 0.044 \\
\hline \multicolumn{7}{|l|}{ Lymphatic invasion } \\
\hline Yes & 733 (40.2\%) & 457 (34.3\%) & 250 (59.0\%) & 26 (38.8\%) & \multirow[t]{2}{*}{$<0.001$} & \multirow[t]{2}{*}{0.001} \\
\hline No & 1089 (59.8\%) & 874 (65.7\%) & $174(41.0 \%)$ & $41(61.2 \%)$ & & \\
\hline \multicolumn{7}{|l|}{ Perineural invasion } \\
\hline Yes & 580 (31.8\%) & 335 (25.2\%) & 222 (52.4\%) & 23 (34.3\%) & \multirow[t]{2}{*}{$<0.001$} & \multirow[t]{2}{*}{0.003} \\
\hline No & $1242(68.2 \%)$ & 996 (74.8\%) & 202 (47.6\%) & $44(65.7 \%)$ & & \\
\hline \multicolumn{7}{|l|}{ Vascular invasion } \\
\hline Yes & 342 (18.8\%) & $221(16.6 \%)$ & $110(25.9 \%)$ & $11(16.4 \%)$ & \multirow[t]{2}{*}{$<0.001$} & \multirow[t]{2}{*}{0.378} \\
\hline No & $1480(81.2 \%)$ & 1110 (83.4\%) & $314(74.1 \%)$ & 56 (83.6\%) & & \\
\hline \multicolumn{7}{|l|}{ Tumor Budding } \\
\hline Positive & 1095 (60.1\%) & 717 (53.9\%) & 331 (78.1\%) & 47 (70.2\%) & \multirow[t]{2}{*}{$<0.001$} & \multirow[t]{2}{*}{0.609} \\
\hline Negative & 727 (39.9\%) & $14(46.1 \%)$ & $93(21.9 \%)$ & 20 (29.8\%) & & \\
\hline \multicolumn{7}{|l|}{ MSI-H } \\
\hline Yes & 115 (6.3\%) & $81(6.1 \%)$ & $22(5.2 \%)$ & $12(17.9 \%)$ & \multirow[t]{2}{*}{$<0.001$} & \multirow[t]{2}{*}{$<0.001$} \\
\hline No & $1684(92.4 \%)$ & 1238 (93.0\%) & $396(93.4 \%)$ & $50(74.6 \%)$ & & \\
\hline Postoperative complication & 79 (4.3\%) & 57 (4.3\%) & $14(3.3 \%)$ & $8(11.9 \%)$ & 0.013 & 0.013 \\
\hline \multicolumn{7}{|l|}{ (CDC $\geq$ grade 3) } \\
\hline Length of stay, mean $\pm S D$, day & $8.74 \pm 13.26$ & $8.72 \pm 15.11$ & $8.34 \pm 5.56$ & $11.79 \pm 6.52$ & $<0.001$ & 0.144 \\
\hline Readmission & $75(4.1 \%)$ & $47(3.5 \%)$ & $21(5.0 \%)$ & 7 (10.5\%) & 0.018 & 0.387 \\
\hline \multicolumn{7}{|l|}{ Adjuvant chemotherapy } \\
\hline Yes & $1332(73.1 \%)$ & $901(67.7 \%)$ & $378(89.2 \%)$ & $53(79.1 \%)$ & \multirow[t]{2}{*}{$<0.001$} & \multirow[t]{2}{*}{0.609} \\
\hline No & 490 (26.9\%) & $430(32.3 \%)$ & $46(10.8 \%)$ & $14(20.9 \%)$ & & \\
\hline Recurrence & $316(17.3 \%)$ & $169(12.7 \%)$ & $127(30.0 \%)$ & $20(29.9 \%)$ & $<0.001$ & $>0.999$ \\
\hline Systemic & $267(84.5 \%)$ & $144(85.2 \%)$ & $109(85.8 \%)$ & $14(70.0 \%)$ & $<0.001$ & $>0.999$ \\
\hline Local & $32(10.1 \%)$ & $18(10.7 \%)$ & $9(7.1 \%)$ & $4(20.0 \%)$ & & \\
\hline Combined & $18(5.6 \%)$ & $7(4.1 \%)$ & $9(7.1 \%)$ & 2 (10.0\%) & & \\
\hline
\end{tabular}

WD, well-differentiated; MD, moderately differentiated; $P D$, poorly differentiated; SD, standard deviation; MSI-H, microsatellite instability-high; CDC, Clavien-Dindo classification.

\section{Cancer-Specific Survival (CSS)}

We also compared CSS among the three groups by stage. Figure 2 shows the CSS curves of the three groups, which are similar to the OS curves. In stage II patients, the 5-year CSS rates were $96.9 \%$ for $\mathrm{T} 3,94.4 \%$ for $\mathrm{T} 4 \mathrm{a}$, and $81.7 \%$ for T4b patients. This difference between the three groups was statistically significant $(\mathrm{p}<0.001)$. The difference between $\mathrm{T} 4 \mathrm{a}$ and $\mathrm{T} 4 \mathrm{~b}$ was also significant $(\mathrm{p}=$ 0.035 ). In stage III patients, the 5 -year CSS survival rates were $94.2 \%$ for $\mathrm{T} 3,77.1 \%$ for $\mathrm{T} 4 \mathrm{a}$, and $66.0 \%$ for $\mathrm{T} 4 \mathrm{~b}$ patients. This difference between the three groups was statistically significant ( $\mathrm{p}<0.001$ ), but there was no significant difference between the T4a and T4b groups ( $\mathrm{p}=0.103$ ) (Figure 2).

In multivariable Cox regression analyses, preoperative CEA, cancer obstruction, node positivity, lymphovascular invasion, perineural invasion, tumor budding, morbidity, and adjuvant chemotherapy status were excluded from the final models to avoid multicollinearity. age less than 60 (HR 0.61, 95\% CI 0.40$0.92, \mathrm{p}=0.020$ ) and well differentiated tumors (poorly differentiated, reference; well differentiated, HR 0.23, 95\% CI 0.09-0.54, $\mathrm{p}=0.001$; moderately differentiated, HR 0.41, 95\% CI $0.23-0.70, \mathrm{p}=0.001$ ) were independent factors for improved CSS, while elevated preoperative CA 19-9 level (HR 1.70, 95\% CI 1.10-
$2.59, \mathrm{p}=0.015)$ and cancer perforation (HR 4.41, 95\% CI 1.72$11.29, \mathrm{p}=0.002$ ) were independent risk factors. Unlike overall survival, T classification was independently associated with CSS; $\mathrm{T} 4 \mathrm{~b}$ showed relatively higher HR than $\mathrm{T} 4 \mathrm{a}$, when respectively compared to T3 (T3, reference; T4a, HR 2.27, 95\% CI 1.37-3.72, $\mathrm{p}<0.001$; T4b, HR 3.53, 95\% CI 1.53-8.08, p < 0.001) (Table 4).

\section{DISCUSSION}

The 1st AJCC guidelines were released in 1977; they have been updated several times over the years, and the 8th edition was published in $2016(17,18)$. There are several changes in the new edition, chief among which is that peritoneal metastasis is included in the new staging system as stage $\operatorname{IV} C(17,19)$.

T4 was first subdivided into T4a and T4b in $2000(20,21)$. This change was incorporated into the 6th edition of the TNM supplement $(21,22)$ and the College of American Pathologists (CAP)-approved protocol for specimen examination of primary CRC patients $(21,23)$. The T4a designation indicated that the tumor directly invades other organs or structures, while T4b indicated that the tumor penetrates the visceral peritoneum 

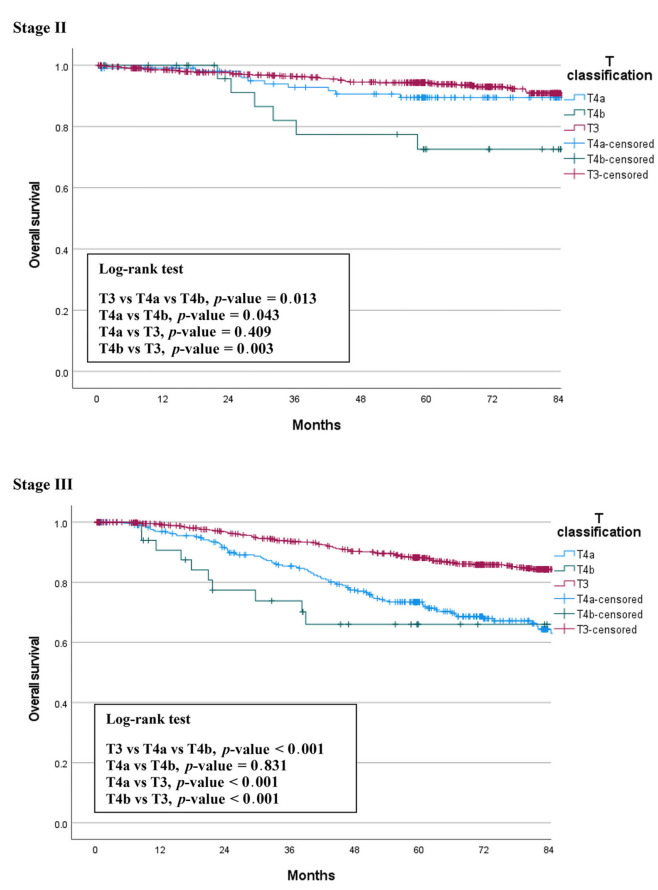

FIGURE 1 | Overall survival of T3 vs. T4 patients by stage.

$(20,21,23)$. However, that was inverted in the 7 th edition of the AJCC guidelines to the present meaning, in which a T4a tumor only penetrates the visceral peritoneum and a $\mathrm{T} 4 \mathrm{~b}$ tumor directly invades or is adherent to other organs or structures (2). According to two studies by Gunderson et al., who analyzed 35,829 rectal cancer and 109,953 colon cancer patients documented in the Surveillance, Epidemiology, and End
Results (SEER) population-based dataset, T4a was associated with a more favorable prognosis than $\mathrm{T} 4 \mathrm{~b}$ for each $\mathrm{N}$ classification of both colon and rectal cancer $(4,5)$. Contrary to these results, a study published in 2019 by Baguena et al. which compared pathologically confirmed T3, T4a, and T4b showed that T4a was an independent risk factor for local recurrence, peritoneal carcinomatosis, worse disease-free survival, and cancer-specific survival, and they suggested that current AJCC classification should be reconsidered (8).

In the present study, we compared three groups of patients with each other to understand the relationship between T4a and T4b based on T3. We found the same trends in the differences between the survival curves of OS and CSS (Figures 1, 2). T4a and T3 showed similar survival rates over time in stage II colorectal cancer patients, but $\mathrm{T} 4 \mathrm{~b}$ was associated with a significant reduction in survival rate. On the contrary, in stage III patients, T4a and T4b showed similar survival rates over time, while T3 showed significantly higher survival rates. These results mean that, for long-term outcomes, in the absence of lymph node metastases, invading other organs or structures is an important factor for prognosis. However, if there are lymph node metastases, the serosal invasion itself, whether T4a or T4b, is more important for prognosis than invasion of other organs. Moreover, in the multivariable Cox analysis, depth of invasion was an independent prognostic factor for CSS; the hazard ratio of T4a and T4b were 2.27 and 3.53, respectively, compared to T3. These results support the current conviction that $\mathrm{T} 4 \mathrm{~b}$ is associated with poorer prognosis than $\mathrm{T} 4 \mathrm{a}$.

We also found that more T4b than T4a patients showed elevated CA 19-9 levels, and that this was an independent risk factor for decreased CSS. Many studies have reported that preoperative elevations in CA 19-9 levels predict poor survival (24-26). Our study showed that elevated preoperative CA19-9 was more indicative of a poor prognosis than elevated

TABLE 3 | Univariable and multivariable cox regression analysis of overall survival.

\begin{tabular}{|c|c|c|c|c|c|c|c|c|}
\hline & \multirow[t]{2}{*}{ Reference } & & \multicolumn{3}{|c|}{ Univariable analysis } & \multicolumn{3}{|c|}{ Multivariable analysis } \\
\hline & & & HR & $95 \% \mathrm{Cl}$ & p-value & HR & $95 \% \mathrm{Cl}$ & p-value \\
\hline \multirow[t]{2}{*}{ T classification } & Т3 & $\mathrm{T} 4 \mathrm{a}$ & 2.5 & $1.82-3.43$ & $<0.001$ & 1.20 & $0.53-2.68$ & $>0.999$ \\
\hline & & $\mathrm{T} 4 \mathrm{~b}$ & 3.21 & $1.70-6.03$ & $<0.001$ & 2.26 & $0.53-9.58$ & 0.532 \\
\hline Age & $\geq 60$ & $<60$ & 0.31 & $0.23-0.41$ & $<0.001$ & 0.39 & $0.20-0.74$ & 0.004 \\
\hline Sex & Female & Male & 1.06 & $0.82-1.35$ & 0.670 & & & \\
\hline Preoperative CEA & $<5$ & $\geq 5$ & 1.58 & $1.22-2.04$ & $<0.001$ & 1.61 & $0.92-2.80$ & 0.094 \\
\hline Preoperative CA19-9 & $<37$ & $\geq 37$ & 1.42 & $1.05-1.90$ & 0.020 & 1.74 & $0.92-3.27$ & 0.087 \\
\hline Cancer obstruction & $N$ & Y & 2.09 & $1.61-2.69$ & $<0.001$ & 0.55 & $0.28-1.05$ & 0.070 \\
\hline Cancer perforation & $N$ & Y & 3.25 & $1.44-7.30$ & 0.004 & 5.00 & $1.51-16.52$ & 0.008 \\
\hline Node positivity & + & - & 0.43 & $0.32-0.57$ & $<0.001$ & 0.55 & 0.3-1.01 & 0.055 \\
\hline \multirow[t]{2}{*}{ Cell differentiation } & PD & WD & 0.38 & $0.22-0.64$ & $<0.001$ & & & \\
\hline & & $\mathrm{MD}$ & 0.55 & $0.36-0.85$ & 0.007 & & & \\
\hline Lymphatic invasion & $\mathrm{N}$ & Y & 1.76 & $1.38-2.25$ & $<0.001$ & & & \\
\hline Perineural invasion & $\mathrm{N}$ & Y & 1.76 & $1.37-2.24$ & $<0.001$ & 1.93 & $1.01-3.67$ & 0.045 \\
\hline Vascular invasion & $\mathrm{N}$ & Y & 2.03 & $1.56-2.65$ & $<0.001$ & & & \\
\hline Tumor budding & $\mathrm{N}$ & Y & 1.69 & $1.29-2.21$ & $<0.001$ & & & \\
\hline MSI-H & $\mathrm{N}$ & Y & 0.74 & $0.41-1.32$ & 0.306 & & & \\
\hline Morbidity (CDC grade $\geq 3$ ) & $\mathrm{N}$ & Y & 2.23 & $1.43-3.45$ & $<0.001$ & 1.87 & $0.98-3.55$ & 0.058 \\
\hline Adjuvant chemotherapy & $N$ & Y & 0.44 & $0.34-0.56$ & $<0.001$ & 0.32 & $0.16-0.61$ & 0.001 \\
\hline
\end{tabular}

CEA, carcinoembryonic antigen; CA 19-9, carbohydrate antigen 19-9; MSI-H, microsatellite instability-high; CDC, Clavien-Dindo classification. 

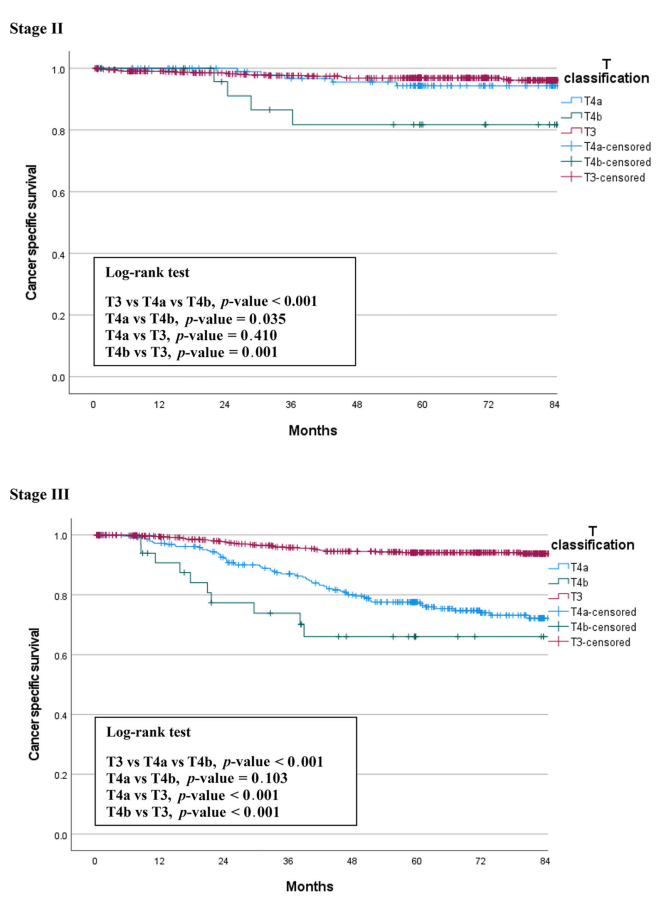

FIGURE 2 | Cancer-specific survival of T3 vs. T4 patients by stage.

preoperative CEA in patients with a tumor invasion depth of T3 or higher. This may indicate that CA 19-9 testing, along with CEA, is a vital part of the preoperative workup, especially for patients with tumor invasion of the muscularis propria and deeper structures. In addition, there were more MSI-H colon cancer patients in the T4b group than in theT4a group. Many studies have shown that MSI-H colon cancer has a better prognosis than MSI-low or microsatellite-stable (MSS) colon cancer (27-30). However, MSI-H was not identified as an independent prognostic factor in our study. The higher proportion of MSI-H in $\mathrm{T} 4 \mathrm{~b}$, which had a poorer prognosis than in T4a, may indicate that MSI status did not have a significant impact on prognosis in T4b, but MSI-H may have been overestimated in $\mathrm{T} 4 \mathrm{~b}$ due to the small number of $\mathrm{T} 4 \mathrm{~b}$ patients. Therefore, further studies with larger numbers are needed.

This study has several limitations. First, this is a retrospective study performed in a single center. Second, it included only a small number of $\mathrm{T} 4 \mathrm{~b}$ colorectal cancer patients, and it may not reflect the true impact of T4b tumor properly. Third, according to the current NCCN guidelines, neoadjuvant chemotherapy is recommended if $\mathrm{T} 4 \mathrm{~b}$ is clinically suspected. However, this recommendation has been included in the NCCN guideline since 2016 (31), so the cases from 2010 to 2014 that included patients in this study were not applicable. Therefore, during this period in our hospital, surgery was performed first if the tumor was completely resectable. And then, if T4b was confirmed in the postoperative pathological examination, adjuvant chemotherapy was recommended. Thus, the survival of $\mathrm{T} 4 \mathrm{~b}$ patients who underwent chemotherapy before surgery according to the current guidelines was not studied. Fourth, genetic tests such as KRAS, NRAS, and BRAF related to prognosis were not performed in all patients, so this could not be analyzed. Fifth, we did not analyze the recurrence or peritoneal seeding according to $\mathrm{T} 4 \mathrm{a} / \mathrm{b}$ classification, which is also an important oncologic outcome. However, this study also has several strengths stemming from its single-center setting which, for example, enabled precise data collection, use of similar treatment protocols in most patients, and the fact that the same multidisciplinary team operated on all of the patients.

TABLE 4 | Univariable and multivariable cox regression analysis of cancer-specific survival.

\begin{tabular}{|c|c|c|c|c|c|c|c|c|}
\hline & & & \multicolumn{3}{|c|}{ Univariable analysis } & \multicolumn{3}{|c|}{ Multivariable analysis } \\
\hline & \multicolumn{2}{|l|}{ Reference } & HR & $95 \% \mathrm{Cl}$ & $\mathrm{p}$-value & HR & $95 \% \mathrm{Cl}$ & p-value \\
\hline \multirow[t]{2}{*}{$\mathbf{T}$ classification } & T3 & $\mathrm{T} 4 \mathrm{a}$ & 4.51 & 2.95-6.90 & $<0.001$ & 2.27 & $1.37-3.72$ & $<0.001$ \\
\hline & & $\mathrm{T} 4 \mathrm{~b}$ & 6.72 & $3.28-13.76$ & $<0.001$ & 3.53 & $1.53-8.08$ & $<0.001$ \\
\hline Age & $\geq 60$ & $<60$ & 0.41 & $0.28-0.58$ & $<0.001$ & 0.61 & $0.40-0.92$ & 0.020 \\
\hline Sex & Female & Male & 0.97 & $0.69-1.34$ & 0.841 & & & \\
\hline Preoperative CEA & $<5$ & $\geq 5$ & 1.60 & $1.14-2.25$ & 0.006 & & & \\
\hline Preoperative CA19-9 & $<37$ & $\geq 37$ & 1.57 & $1.07-2.27$ & 0.019 & 1.70 & $1.10-2.59$ & 0.015 \\
\hline Cancer obstruction & $N$ & Y & 2.60 & $1.86-3.62$ & $<0.001$ & & & \\
\hline Cancer perforation & $\mathrm{N}$ & Y & 4.72 & 1.93-11.52 & $<0.001$ & 4.41 & $1.72-11.29$ & 0.002 \\
\hline Node positivity & + & - & 0.32 & $0.21-0.48$ & $<0.001$ & & & \\
\hline \multirow[t]{2}{*}{ Cell differentiation } & PD & WD & 0.19 & 0.09-0.39 & $<0.001$ & 0.23 & $0.09-0.54$ & 0.001 \\
\hline & & $\mathrm{MD}$ & 0.41 & $0.25-0.67$ & $<0.001$ & 0.41 & $0.23-0.70$ & 0.001 \\
\hline Lymphatic invasion & $\mathrm{N}$ & Y & 2.56 & $1.82-3.59$ & $<0.001$ & & & \\
\hline Perineural invasion & $\mathrm{N}$ & Y & 2.66 & $1.91-3.77$ & $<0.001$ & & & \\
\hline Vascular invasion & $\mathrm{N}$ & Y & 2.69 & $1.92-3.77$ & $<0.001$ & & & \\
\hline Tumor budding & $\mathrm{N}$ & Y & 2.14 & $1.46-3.13$ & $<0.001$ & & & \\
\hline MSI-H & $\mathrm{N}$ & Y & 0.64 & $0.28-1.46$ & 0.291 & & & \\
\hline Morbidity (CDC grade $\geq 3$ ) & $\mathrm{N}$ & Y & 2.58 & $1.49-1.49$ & $<0.001$ & & & \\
\hline Adjuvant chemotherapy & $\mathrm{N}$ & Y & 0.14 & $0.05-0.38$ & $<0.001$ & & & \\
\hline
\end{tabular}

CEA, carcinoembryonic antigen; CA 19-9, carbohydrate antigen 19-9; WD, well-differentiated; MD, moderately differentiated; PD, poorly differentiated; MSI-H, microsatellite instabilityhigh; CDC, Clavien-Dindo classification. 
In conclusion, T4a was associated with greater OS and CSS rates than $\mathrm{T} 4 \mathrm{~b}$, especially in stage II patients. Moreover, $\mathrm{T}$ classification was an independent risk factor in CSS, with a higher hazard ratio seen in $\mathrm{T} 4 \mathrm{~b}$ than $\mathrm{T} 4 \mathrm{a}$ compared to $\mathrm{T} 3$ patients. The findings of the present study support the current AJCC guideline that T4b tumors are at a more advanced stage than T4a tumors, and that preoperative CA 19-9 measurements are essential for predicting prognosis. A multicenter study with a larger sample size and more data on the relationship between recurrence and $\mathrm{T} 4 \mathrm{a} / \mathrm{T} 4 \mathrm{~b}$ staging is needed.

\section{DATA AVAILABILITY STATEMENT}

The raw data supporting the conclusions of this article will be made available by the authors, without undue reservation.

\section{REFERENCES}

1. Ministry of Health and Welfare. Cancer Incidence and Death Status (2020). Available at: https://www.index.go.kr/potal/main/EachDtlPageDetail.do?idx_ $\mathrm{cd}=2770$ (Accessed 2 January 2 2021).

2. Edge SB, Byrd DR, Compton CC, Fritz AG, Greene FL, Trotti A. AJCC Cancer Staging Manual. 7th. New York: Springer (2010).

3. Lorenzon L, Pilozzi E, La Torre M, Ziparo V, Ferri M. Impact and Prognostic Implications of Colon Cancers Stage II Sub-Classification Through the Years. Int J Colorectal Dis (2012) 27(10):1311-8. doi: 10.1007/ s00384-012-1475-x

4. Gunderson LL, Jessup JM, Sargent DJ, Greene FL, Stewart A. Revised Tumor and Node Categorization for Rectal Cancer Based on Surveillance, Epidemiology, and End Results and Rectal Pooled Analysis Outcomes. J Clin Oncol (2010) 28:256-63. doi: 10.1200/JCO.2009.23.9194

5. Gunderson LL, Jessup JM, Sargent DJ, Greene FL, Stewart AK. Revised TN Categorization for Colon Cancer Based on National Survival Outcomes Data. J Clin Oncol (2010) 28:264-71. doi: 10.1200/JCO.2009.24.0952

6. Shia J, Klimstra DS, Bagci P, Basturk O, Adsay NV. TNM Staging of Colorectal Carcinoma: Issues and Caveats. Semin Diagn Pathol (2012) 29:142-53. doi: 10.1053/j.semdp.2012.02.001

7. Pollheimer MJ, Kornprat P, Pollheimer VS, Lindtner RA, Schlemmer A, Rehak P, et al. Clinical Significance of pT Sub-Classification in Surgical Pathology of Colorectal Cancer. Int J Colorectal Dis (2010) 25:187-96. doi: 10.1007/s00384-009-0801-4

8. Baguena G, Pellino G, Frasson M, Rosello S, Cervantes A, Garcia-Granero A, et al. Prognostic Impact of pT Stage and Peritoneal Invasion in Locally Advanced Colon Cancer. Dis Colon Rectum (2019) 62:684-93. doi: 10.1097/ DCR.0000000000001367

9. Park JS, Choi GS, Hasegawa S, Sakai Y, Huh JW, Kim HR, et al. Validation of the Seventh Edition of the American Joint Committee on Cancer Tumor Node-Staging System in Patients With Colorectal Carcinoma in Comparison With Sixth Classification. J Surg Oncol (2012) 106:674-9. doi: 10.1002/ jso. 23117

10. Lan YT, Yang SH, Chang SC, Liang WY, Li AF, Wang HS, et al. Analysis of the Seventh Edition of American Joint Committee on Colon Cancer Staging. Int $J$ Colorectal Dis (2012) 27(5):657-63. doi: 10.1007/s00384-011-1366-6

11. Amin MB, Edge S, Greene F, Byrd DR, Brookland RK, Washington MK, et al. AJCC Cancer Staging Manual. 8th. New York: Springer (2017).

12. Lee SC, Huh JW, Lee WY, Yun SH, Kim HC, Cho YB, et al. Long-Term Oncologic Outcome and Risk Factors After Conversion in Laparoscopic Surgery for Colon Cancer. Int J Colorectal Dis (2020) 35:395-402. doi: 10.1007/s00384-019-03489-7

13. Shin JK, Kim HC, Lee WY, Yun SH, Cho YB, Huh JW, et al. Laparoscopic Modified Mesocolic Excision With Central Vascular Ligation in Right-Sided Colon Cancer Shows Better Short- and Long-Term Outcomes Compared

\section{ETHICS STATEMENT}

The studies involving human participants were reviewed and approved by Institutional Review Board of Samsung Medical Center. Written informed consent for participation was not required for this study in accordance with the national legislation and the institutional requirements.

\section{AUTHOR CONTRIBUTIONS}

$\mathrm{JL}$ and JH contributed to conception and design of the study. JL, JH, WL, SY, HK, YC, YP, and JS organized the database. JL performed the statistical analysis. JL and JH wrote the first draft of the manuscript. All authors contributed to manuscript revision, read, and approved the submitted version.

With the Open Approach in Propensity Score Analysis. Surg Endosc (2018) 32:2721-31. doi: 10.1007/s00464-017-5970-6

14. Park JS, Huh JW, Park YA, Cho YB, Yun SH, Kim HC, et al. Clinically Suspected T4 Colorectal Cancer may be Resected Using a Laparoscopic Approach. BMC Cancer (2016) 16:714. doi: 10.1186/s12885-016-2753-8

15. Clavien PA, Sanabria JR, Strasberg SM. Proposed Classification of Complications of Surgery With Examples of Utility in Cholecystectomy. Surgery (1992) 111:518-26.

16. Dindo D, Demartines N, Clavien PA. Classification of Surgical Complications: A New Proposal With Evaluation in a Cohort of 6336 Patients and Results of a Survey. Ann Surg (2004) 240:205-13. doi: 10.1097/01.sla.0000133083.54934.ae

17. Weiser MR. AJCC 8th Edition: Colorectal Cancer. Ann Surg Oncol (2018) 25:1454-5. doi: 10.1245/s10434-018-6462-1

18. American Joint Committee on Cancer. Cancer Staging Manual (2020). Available at: https://cancerstaging.org/references-tools/deskreferences/Pages/ defaultaspx (Accessed 2 January 2 2021).

19. Tong GJ, Zhang GY, Liu J, Zheng ZZ, Chen Y, Niu PP, et al. Comparison of the Eighth Version of the American Joint Committee on Cancer Manual to the Seventh Version for Colorectal Cancer: A Retrospective Review of Our Data. World J Clin Oncol (2018) 9:148-61. doi: 10.5306/wjco.v9.i7.148

20. Compton C, Fenoglio-Preiser CM, Pettigrew N, Fielding LP. American Joint Committee on Cancer Prognostic Factors Consensus Conference: Colorectal Working Group. Cancer (2000) 88:1739-57. doi: 10.1002/(sici)1097-0142 (20000401)88:7<1739::aid-cncr30>3.0.co;2-t

21. Puppa G, Sonzogni A, Colombari R, Pelosi G. TNM Staging System of Colorectal Carcinoma: A Critical Appraisal of Challenging Issues. Arch Pathol Lab Med (2010) 134:837-52. doi: 10.1043/1543-2165-134.6.837

22. Wittekind C, Henson DE, Hutter RV, Sobin LH. TNM Supplement: A Commentary on Uniform Use. 3rd. Hoboken, New Jersey: John Wiley \& Sons (2003).

23. Compton CC, Members of the Cancer Committee and College of American Pathologists. Carcinoid Tumors, Lymphomas, Sarcomas, and Tumors of the Vermiform Appendix Are Excluded. In: Colon and Rectum: Protocol Applies to All Invasive Carcinomas of the Colon and Rectum (2005). Available at: https://www.cap.org/apps/docs/cancer_protocols/2005/colonrectum05_ckw. pdf (Accessed 2 January 2 2021).

24. Lee T, Teng TZJ, Shelat VG. Carbohydrate Antigen 19-9 - Tumor Marker: Past, Present, and Future. World J Gastrointest Surg (2020) 12:468-90. doi: 10.4240 /wjgs.v12.i12.468

25. Shin JK, Kim HC, Lee WY, Yun SH, Cho YB, Huh JW, et al. High Preoperative Serum CA 19-9 Levels Can Predict Poor Oncologic Outcomes in Colorectal Cancer Patients on Propensity Score Analysis. Ann Surg Treat Res (2019) 96:107-15. doi: 10.4174/astr.2019.96.3.107

26. Halilovic E, Rasic I, Sofic A, Mujic A, Rovcanin A, Hodzic E, et al. The Importance of Determining Preoperative Serum Concentration of Carbohydrate Antigen 19-9 and Carcinoembryonic Antigen in Assessing 
the Progression of Colorectal Cancer. Med Arch (2020) 74:346-9. doi: 10.5455/medarh.2020.74.346-349

27. Gryfe R, Kim H, Hsieh ET, Aronson MD, Holowaty EJ, Bull SB, et al. Tumor Microsatellite Instability and Clinical Outcome in Young Patients With Colorectal Cancer. N Engl J Med (2000) 342(2):69-77. doi: 10.1056/NEJM200001133420201

28. Popat S, Hubner R, Houlston RS. Systematic Review of Microsatellite Instability and Colorectal Cancer Prognosis. J Clin Oncol (2005) 23(3):60918. doi: 10.1200/JCO.2005.01.086

29. Saridaki Z, Souglakos J, Georgoulias V. Prognostic and Predictive Significance of MSI in Stages II/III Colon Cancer. World J Gastroenterol (2014) 20 (22):6809-14. doi: 10.3748/wjg.v20.i22.6809

30. Oh BY, Huh JW, Park YA, Cho YB, Yun SH, Kim HC, et al. Prognostic Factors in Sporadic Colon Cancer With High-Level Microsatellite Instability. Surgery (2016) 159(5):1372-81. doi: 10.1016/j.surg.2015.11.028

31. Benson AB 3rd, Venook AP, Cederquist L, Chan E, Chen Y-J, Cooper HS, et al. Colon Cancer, Version 1.2017, NCCN Clinical Practice Guidelines in Oncology. J Natl Compr Canc Netw (2017) 15(3):370-98. doi: 10.6004/jnccn.2017.0036
Conflict of Interest: The authors declare that the research was conducted in the absence of any commercial or financial relationships that could be construed as a potential conflict of interest.

Publisher's Note: All claims expressed in this article are solely those of the authors and do not necessarily represent those of their affiliated organizations, or those of the publisher, the editors and the reviewers. Any product that may be evaluated in this article, or claim that may be made by its manufacturer, is not guaranteed or endorsed by the publisher.

Copyright $\odot 2022$ Lim, Huh, Lee, Yun, Kim, Cho, Park and Shin. This is an openaccess article distributed under the terms of the Creative Commons Attribution License (CC BY). The use, distribution or reproduction in other forums is permitted, provided the original author(s) and the copyright owner(s) are credited and that the original publication in this journal is cited, in accordance with accepted academic practice. No use, distribution or reproduction is permitted which does not comply with these terms. 